\title{
The Wellbeing Economics Framework
}

\begin{abstract}
This chapter summarises key points in the wellbeing economics framework and illustrates how it can be used to guide decision-making. The first section lists the 24 propositions that emerged as key points in the analysis of the preceding eight chapters. The second section introduces a diagram that integrates inputs into wellbeing capabilities (7 types of capital stock) with outputs of wellbeing capabilities ( 11 wellbeing indicators developed by the Organisation for Economic Co-operation and Development). The diagram is called the wellbeing fabric. The remainder of the chapter illustrates how the wellbeing fabric can be applied at different levels of human choices, before a brief conclusion.
\end{abstract}

Keywords Wellbeing economics • Wellbeing fabric • Economic policy • Capabilities • Skills

Despite international initiatives "to shift emphasis from measuring economic production to measuring people's well-being" (Stiglitz et al. 2009, p. 12), policy decisions in many nations continue to prioritise high economic growth over other objectives. In the United Kingdom, for example, this priority was emphasised by former Prime Minister David Cameron's (2010), even as he launched the country's Measuring National Wellbeing Programme, when he insisted that "growth is the essential foundation of all our aspirations". 
That statement holds that growth is a necessary, although perhaps not sufficient, condition for wellbeing. This understanding leaves policy advisors free to focus on growth in the first instance, while allowing for supplementary policies to address other aspects of wellbeing. A sharp distinction is made between economic policy, which is required to focus primarily on growth, and social policy, which is permitted to have a wider focus on welfare. Where there is conflict, priority is always given to economic policy, as demonstrated in the United Kingdom's austerity measures after the global financial crisis.

This book rejects that two-tier approach. It has argued that how economies grow can have large impacts on wellbeing, for better or for worse. Economic growth over decades, for example, has not solved major wellbeing problems such as affordable housing, living wages and the end of child poverty. There is clear scientific evidence of severe risks to future wellbeing on a global scale as a result of climate change caused by greenhouse gas emissions that are "driven largely by economic and population growth" (IPCC 2015, p. 4; see also Jackson 2017). This book has argued that the current approach to the design of economic policy must change, to directly address the wellbeing of persons.

The book has therefore developed a wellbeing economics framework built on the capabilities approach introduced by Amartya Sen $(1983,1999)$ and Martha Nussbaum $(2000,2011)$. Important foundations for the framework were set out in the first chapter, which explained that the objective is to contribute to enhanced wellbeing of persons by expanding the capabilities of persons to lead the kinds of lives they value, and have reason to value, through different types of capital investment at different levels of human choice.

Chapters 2, 3, 4, 5, 6, 7 and 8 then addressed seven levels of human choices, reproduced in Fig. 9.1. The analysis began in Chap. 2 with persons making time-use choices about activities they anticipate will contribute to the kinds of life they value, and have reason to value. Successive chapters analysed how expanding levels of collaboration can increase capabilities for wellbeing.

This final chapter summarises key points in the wellbeing economics framework and illustrates how the framework can be used to guide decision-making at the different levels shown in Fig. 9.1. The first section lists the 24 propositions that emerged as key points in the preceding eight chapters. The second section then brings together capabilities and capital stocks into a single diagram, which we call the wellbeing fabric. It is designed to assist decision-makers think about influences on wellbeing in an integrated manner.

The subsequent three sections illustrate how the wellbeing fabric can be applied at the different levels of human choice shown in Fig. 9.1. The first sec- 


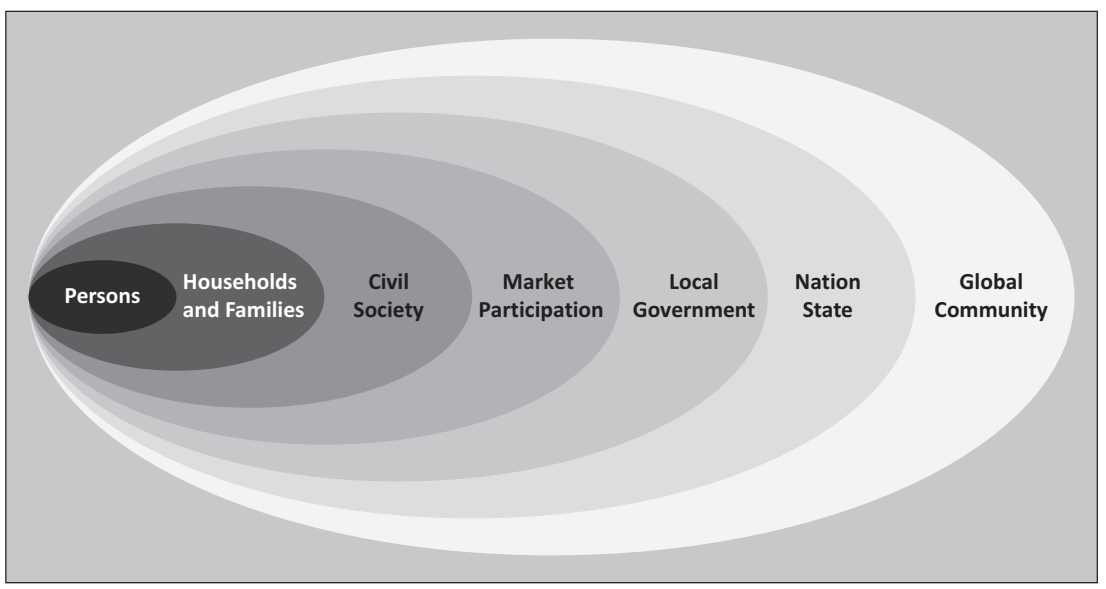

Fig. 9.1 Levels of human choice in the wellbeing economics framework. (Source: Fig. 1.1 in Chap. 1)

tion discusses the wellbeing of individuals, households and families, taken together. The second section illustrates how institutions of civil society, firms in the market economy and initiatives of local government combine capital stocks in distinctive ways to create greater capabilities for wellbeing than households and families can achieve in isolation. This is followed by a section on the Nation State, discussing how the wellbeing fabric can be used to guide national and international collaborations to promote wellbeing. The chapter concludes with some final comments.

\section{The Propositions of Wellbeing Economics}

Each chapter in this book has recorded three propositions that note key points in the analysis. The resulting 24 propositions offer a structured summary of the wellbeing economics framework, and are presented here in a single list for the convenience of the reader.

\section{Foundations of the Framework}

Proposition 1 The primary purpose of economics is to contribute to enhanced wellbeing of persons. 
Proposition 2 Wellbeing can be enhanced by expanding the capabilities of persons to lead the kinds of lives they value, and have reason to value.

Proposition 3 The capabilities of persons can be expanded by different types of capital investment at different levels of human choice.

\section{Persons and Human Capital}

Proposition 4 Persons can make time-use choices they reason will promote wellbeing, influenced by their cultural values, personal abilities and social capabilities.

Proposition 5 Investment in human capital through education can provide persons, in all their diversity, with opportunities to discover, discipline and display skills that contribute to wellbeing.

Proposition 6 Personal wellbeing can be monitored using a set of indicators that include measures of subjective and objective wellbeing, supplemented by measured trends in different types of capital.

\section{Households, Families and Cultural Capital}

Proposition 7 Investment in cultural capital can enhance the wellbeing of households and families by expanding opportunities to express, develop, transform and pass on to the next generation their cultural inheritance.

Proposition 8 Men and women can have equal capabilities for wellbeing.

Proposition 9 Present and future wellbeing can be enhanced if children grow up in households that are able to access adequate economic resources.

\section{Civil Society and Social Capital}

Proposition 10 Persons can access enhanced capabilities for wellbeing by participating in institutions of civil society to collaborate with others in the pursuit of common interests and shared values. 
Proposition 11 Investment in social capital can occur through mechanisms that include: learning in schools; participation in networks; enforcement of norms; development of societal aspirations; and efforts for social inclusion.

Proposition 12 Policy can enhance capabilities for wellbeing by ensuring persons are not disadvantaged in their equitable access to services from the country's capital stocks because of ethnicity or other personal characteristics.

\section{Market Participation and Economic Capital}

Proposition 13 Persons can enhance wellbeing by participating as sellers and as buyers in the market economy; but markets need rules, customs and institutions to work well.

Proposition 14 Firms operating in the market economy can combine different types of capital to maintain specialist capabilities for supplying goods and services valued by their customers.

Proposition 15 Investment in physical capital and the growth of financial capital can contribute to enhanced wellbeing, but recent patterns of economic development are also associated with cumulative environmental damage, episodes of financial instability and greater concentration of wealth.

\section{Local Government and Natural Capital}

Proposition 16 Good government can develop distinctive capabilities for managing the provision of certain types of goods and services, especially those with externalities or the characteristics of an economic public good.

Proposition 17 Local government, sharing leadership with other actors in their communities, can develop and sustain regional capabilities for wellbeing through integrated investment in different types of capital.

Proposition 18 Human activity can diminish ecosystem services provided by the natural environment, and so investment in natural capital is required to maintain and enhance wellbeing. 


\section{The Nation State and Knowledge Capital}

Proposition 19 The Nation State can contribute to expanded capabilities for wellbeing by acting on behalf of citizens as wise custodian of the market economy and welfare state within its borders.

Proposition 20 Knowledge capital has the properties of an economic public good, so that Nation States can contribute to enhanced wellbeing by fostering the growth and use of knowledge.

Proposition 21 The civil service can offer a specialist capability for creating, collating, synthesising, utilising and disseminating knowledge capital for the common good.

\section{The Global Community and Diplomatic Capital}

Proposition 22 International non-governmental organisations, multinational corporations and intergovernmental organisations can increase opportunities for global collaboration.

Proposition 23 The global research community can develop knowledge by following well-established norms and protocols to build an interconnected corpus of publications that offer evidence for falsifiable propositions.

Proposition 24 Investment in diplomatic capital (that is, in institutions and norms designed to foster cross-cultural collaborations) can strengthen the capabilities of the global community to act together for the common good.

\section{The Wellbeing Fabric}

Recall from the opening chapter that our approach to wellbeing capabilities is inspired by Solow's (1956) neoclassical growth model. Solow demonstrated how increasing the share of production devoted to physical capital investment can increase material living standards. Physical capital is one type of capital contributing to capabilities, and average material living standards is one measure of wellbeing outcomes. The wellbeing economics framework covers a wider 
range of capitals and wellbeing outcomes, but the fundamental insight is the same as Solow's: capabilities for wellbeing are expanded by investment in capital stocks.

Chapter 2 discussed an important debate about how a list of capabilities should be determined. Sen (2004) argues this determination should be made by members of each community exercising their own agency. Nussbaum (2003) argues that a list of central human capabilities can be developed to reflect the fundamental dignity of the human person, while being sensitive to cultural difference and open to change. Our approach avoids determining capabilities directly, but recognises inputs into capabilities (the different types of capital stock) and outputs of capabilities (wellbeing outcomes). This creates a matrix diagram that we term the wellbeing fabric, depicted in Fig. 9.2. ${ }^{1}$

\begin{tabular}{|c|c|c|c|c|c|c|c|c|}
\hline \multirow{2}{*}{\multicolumn{2}{|c|}{$\begin{array}{l}\text { Capital stocks expand the } \\
\text { capabilities of persons } \\
\text { to increase outcomes for } \\
\text { wellbeing. }\end{array}$}} & \multicolumn{7}{|c|}{ Measures of Capital Stocks } \\
\hline & & 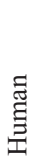 & \multirow[t]{2}{*}{ U } & \multirow[t]{2}{*}{$\begin{array}{l}\bar{\pi} \\
\frac{\pi}{2} \\
0 \\
\infty\end{array}$} & \multirow[t]{2}{*}{ 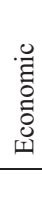 } & \multirow[t]{2}{*}{ 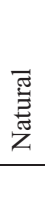 } & \multirow[t]{2}{*}{$\begin{array}{l}0 \\
\frac{80}{0} \\
\frac{0}{3} \\
0 \\
\vdots \\
1\end{array}$} & 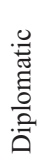 \\
\hline \multirow{11}{*}{ 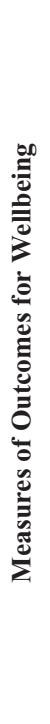 } & Income and Wealth & & & & & & & \\
\hline & Jobs and Earnings & & & & & & & \\
\hline & Housing & & & & & & & \\
\hline & Health Status & & & & & & & \\
\hline & Work-Life Balance & & & & & & & \\
\hline & Education and Skills & & & & & & & \\
\hline & Social Connections & & & & & & & \\
\hline & $\begin{array}{l}\text { Civic Engagement } \\
\text { and Governance }\end{array}$ & & & & & & & \\
\hline & Environmental Quality & & & & & & & \\
\hline & Personal Security & & & & & & & \\
\hline & Subjective Wellbeing & & & & & & & \\
\hline
\end{tabular}

Fig. 9.2 Wellbeing fabric of capital stocks and outcomes for wellbeing. (Source: Constructed from $\operatorname{OECD}$ (2013, Fig. 1.2, p. 21, reproduced in Fig. 2.3 of this book) and from Table 1.1) 
The rows in the diagram contain measures of outcomes for wellbeing taken from the OECD's (2013) wellbeing conceptual framework, which was designed to reflect elements of Sen's capabilities approach (OECD 2017, p. 23). That list identifies 10 measures of objective wellbeing and adds subjective wellbeing as an 11th measure (see Fig. 2.3 of Chap. 2). These measures provide a reasonable structure for monitoring the changes over time in wellbeing outcomes from capabilities. Capabilities are developed by drawing on capital investment. The columns of Fig. 9.2 therefore measure each of the seven types of capital stock identified in the framework, originally listed in Table 1.1.

The following three sections illustrate how this wellbeing fabric can be used.

\section{Individuals, Households and Families}

The emphasis throughout this book has been on "persons leading the kinds of lives they value, and have reason to value" (Sen 1999, p. 18). Persons are members of households and families, and critical choices at key moments are often made with wider family involvement, influenced by cultural norms that are transformed and passed down through the generations (see, e.g., Buunk et al. 2010; Shockley et al. 2017). This section therefore considers individuals, households and families taken together.

The process of determining the kinds of lives we value, and have reason to value, is dynamic and conflicted. Values are continuously negotiated in a person's relations with others (White 2017). This is experienced most intensely within households and families, although influenced by wider social and cultural connections. The wellbeing economics framework has little to say about that process, but the wellbeing fabric is a tool for considering the range of inputs into, and outcomes from, the capabilities that people need to live their chosen lives.

The connection between the warp and weft of the wellbeing fabric is recorded in its first cell: capital stocks expand the capabilities of persons to increase outcomes for wellbeing. To illustrate, consider Education and Skills, which is a wellbeing outcome from capabilities that develop over a person's lifetime from an early age. During the person's school years, that development depends on the quality of seven types of capital that schools provide:

- Human capital, in the form of diversely skilled teachers and the school managers

- Cultural capital, in the form of education experiences that respect and support expression of cultural values and practices 
- Social capital, in the form of norms and networks within the school that support collaboration and develop skills for future collaborations in wider society

- Economic capital, in the form of purpose built buildings, classrooms and equipment that support effective learning

- Natural capital, in the form of sports grounds, field trips and a safe environment at school (e.g., clean air)

- Knowledge capital, in the form of world-class best-practices for learning that are embedded in the school's teaching

- Diplomatic capital, in the form of opportunities to learn skills (including foreign languages) needed to engage in global initiatives to improve wellbeing

It is easy to write similar bullet points describing how each of the outcomes in the wellbeing fabric depends on access to the seven types of capital stock. The result is a tool for understanding causes of low wellbeing and for identifying potential solutions.

Using the rows of Fig. 9.2, for example, it is possible to determine which of the measures reflect low levels of outcomes for wellbeing in a group relative to the rest of the population. There is likely to be more than one. Poor housing, for example, typically leads to poor health. Poor health typically leads to poor education and skills, which typically lead to poor jobs and earnings. Poor jobs and earnings typically lead back to poor housing, creating a negative spiral of reduced wellbeing.

Using the columns of Fig. 9.2, it is then possible to investigate both the extent and the quality of each type of the seven capital stocks made available to a group with low wellbeing. Poor outcomes for education and skills, for example, may be due to the low quality of one or more of the capital stocks. Similarly, a region might be struggling with high levels of unemployment compared to the national average. The analysis might conclude that a contributing factor is reduced access to quality economic capital due to deindustrialisation (Tregenna 2009; van Neuss 2018).

To give another important illustration, recall the personal security data in Chap. 3. Figure 3.3 showed that UK women are much more likely than men to report intimate violence since the age of 16 , with the likelihood being greater than two to one for partner abuse, and greater than five to one for sexual assault. The wellbeing fabric invites an analysis of how this female vulnerability might be affected by gender inequality in access to the seven capital stocks, resulting in women, on average, having fewer economic opportunities than male peers (Aizer 2010). 
To address this, action is required to ensure women have equal access to quality human capital from an early age through to adulthood, to be able to attain the same level of education and skills as men. Action is required to ensure women have equal access to social capital, and so can make social connections with dominant networks. Action is required to ensure women have equal access to economic capital in firms, and so can access the same quality jobs and earnings. Action is required to ensure women have equal access to diplomatic capital, and so are able to participate equally with men in civic engagement and governance.

These examples illustrate that individuals or households acting in isolation may have little power for improving access to capital stocks in the face of powerful economic and social trends. Progress often requires collaboration on a wider and larger scale, as discussed in the following section.

\section{Civil Society, Market Firms and Local Government}

Wellbeing is enhanced by bringing together different types of capital to create capabilities. An individual, household or family may be able to do this on a small scale, but capabilities are usually expanded by specialist organisations, including institutions of civil society (Proposition 10), firms in the market economy (Proposition 14) and initiatives of local and central government (Propositions 16, 17, 19 and 21). Persons and households then use the goods and services provided by these organisations to enhance wellbeing outcomes according to their own values.

Consider again the example of developing education and skills during a person's school years. Some families provide home schooling within their own households (Kraftl 2012), but more typically the work of bringing together human, cultural, social, economic, natural, knowledge and diplomatic capital for education is the responsibility of specialist institutions - that is, schoolscreated for this purpose.

That example can be generalised into a description of how organisations contribute to wellbeing. An organisation identifies goods or services it can provide to increase the capabilities for wellbeing of individuals, households and families. The organisation then brings together the different types of capital needed to create the capability to produce and deliver those goods or services. The nature of the organisation-whether it is an institution of civil society, a firm in the 
market economy or an initiative of local government-depends largely on the characteristics of the goods or services.

Civil society institutions thrive when goods or services rely on the time and financial donations of volunteers who are motivated by the pursuit of common interests and shared values (see Chap. 4). As stated in Proposition 10, members of these institutions access enhanced capabilities through participation. This includes collective action in solidarity with social peers. Throughout history, for example, women have come together in organised campaigns for equality with men in the private and public sphere.

Another example of collective action reliant on member participation is the trade union movement. This civil society institution has a long tradition in the United Kingdom (Thompson 1963; Oswald 1985; Aldcroft and Oliver 2017), but has declined over the last three decades. Figure 9.3 shows UK trade union membership as a percentage of employed and working-age populations since 1960. These series peaked around 1980 and have fallen steadily since then. This is likely to have had consequences for pay and conditions in some industries, including rewards for skilled work and the protection of living wages.

Many goods and services are provided by firms in the market economy, at least to those who can afford to purchase them. As discussed in Chap. 5, there

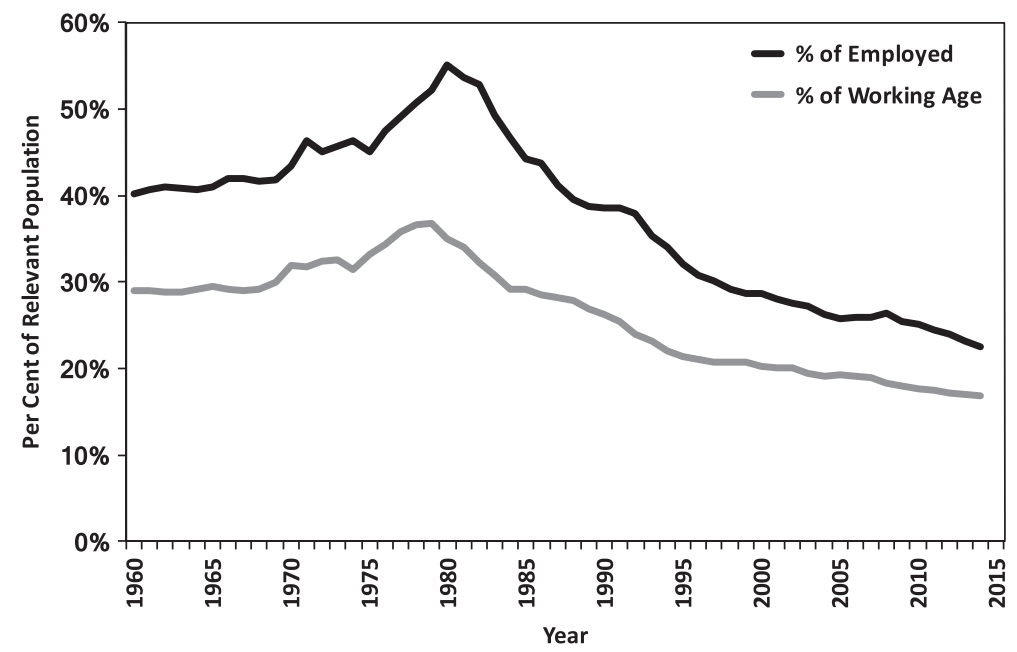

Fig. 9.3 Trade union membership, percentage of employed and working-age populations, United Kingdom, 1960-2014. (Source: Department for Business, Energy \& Industrial Strategy, Trade Union Statistics, and OECD, Employment and Labour Market Statistics) 
is a well-established capability theory of firms in the economics literature (Teece 2017a, b). Proposition 14 summarises the key insight: Firms operating in the market economy combine different types of capital to maintain specialist capabilities for supplying goods and services valued by their customers. As discussed in Chap. 2, the value of a good or service in the market economy is founded on the contribution it makes to the benefits from time-use choices of persons creating the kinds of lives they value. Hence, firms are rewarded for delivering value.

Some types of goods and services are not supplied efficiently in the market economy. Proposition 16 elaborates that good government has distinctive capabilities to ensure goods and services that involve externalities, as well as economic public goods, are provided for wellbeing. Discussion around that proposition explained that if a public sector initiative can be greatly improved by local residents actively participating in its design or implementation, then this is a reason for the initiative to be overseen by local rather than central government (Lyons 2007, par. 2.8).

A second way in which local government contributes to enhanced capabilities is through co-production of regional development. This is summarised in Proposition 17: local government, sharing leadership with other actors in their communities, can develop and sustain regional capabilities for wellbeing through integrated investment in different types of capital. This role is distinctive because it does not involve the local government supplying goods and services; rather, the aim is to co-produce integrated strategies with other actors (including central government agencies) in which coordinated actions by various stakeholders can enhance capabilities for wellbeing (Ostrom 2010). Figure 9.4 presents a flowchart of how this can be achieved in practice. It comes from a diagram first presented in Saunders and Dalziel (2004), but developed further using the ideas behind the columns and rows of the wellbeing fabric in Fig. 9.2.

On the left-hand side of Fig. 9.4, an analysis is made of the available stocks of different forms of capital in the region and trends over time. On the right-hand side, processes are implemented to obtain the views of residents on what outcomes are valued for wellbeing (including consultation with institutions of civil society), alongside a dialogue with the business sector for insights on how to relax key constraints on promoting wellbeing. A third stream of work reviews the provision of public services to identify gaps and opportunities for enhancing capabilities.

This allows gaps and opportunities in regional capabilities to be identified, which provides a foundation for co-produced strategies to fill the gaps and take 


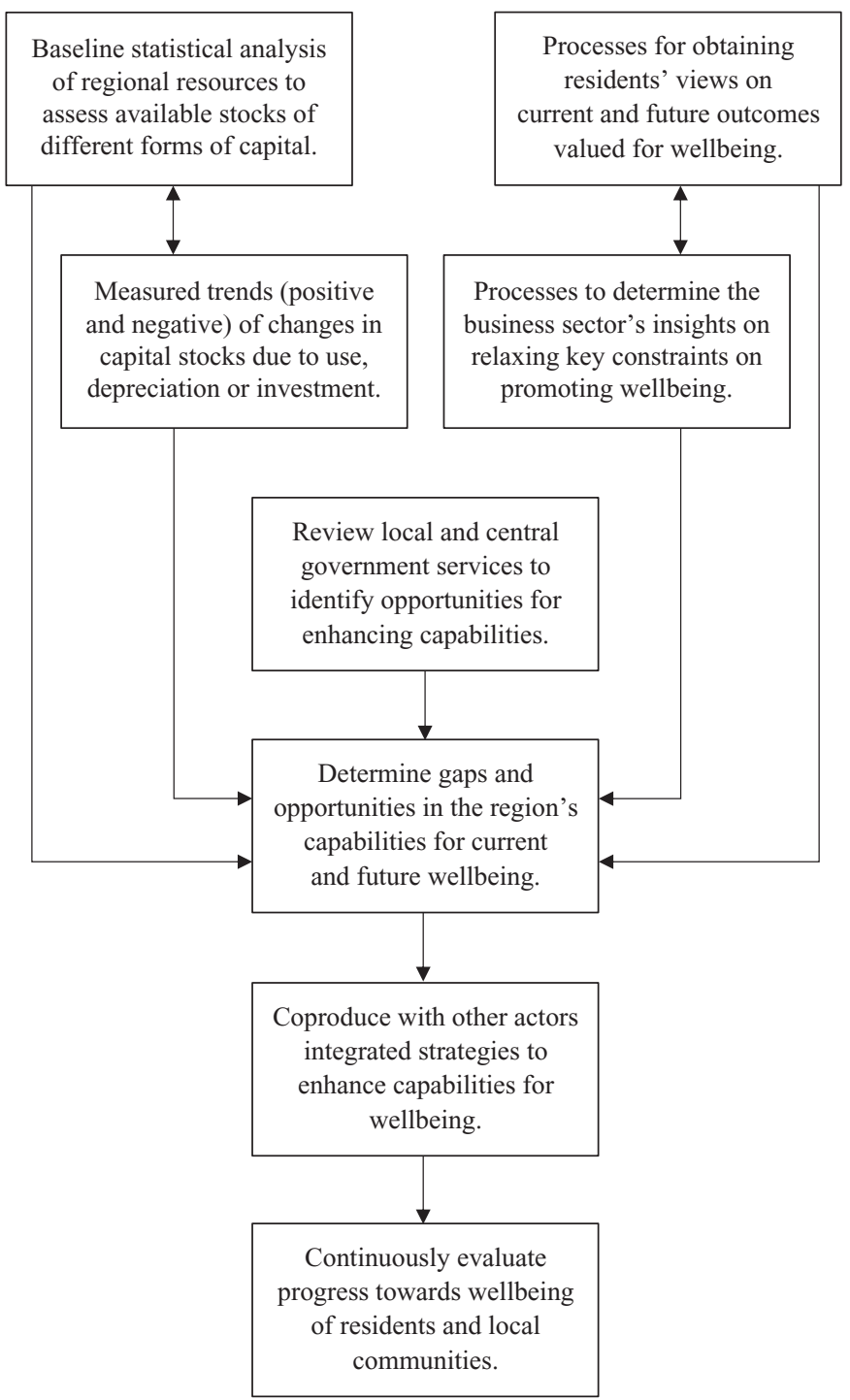

Fig. 9.4 Framework for local government action. (Source: Developed from Saunders and Dalziel (2004, Fig. 1, p. 364)) 
advantage of the opportunities. The final step is to evaluate progress towards the strategy's goals.

\section{The Nation State}

In many respects, the Nation State is simply a higher level of government operating at a larger scale than local government. Proposition 16 applies: the state has distinctive capabilities at the national level in ensuring access to goods and services that involve externalities, as well as economic public goods. Chap. 7 emphasised the state's role, including through its civil service, in contributing to enhanced wellbeing by fostering the growth and use of knowledge (Propositions 20 and 21).

The role of the state in addressing market failures such as externalities, economic public goods, monopolies and imperfect information is an important function. Another is to act as wise custodian of the market economy and welfare state within its borders (Proposition 19).

Recall from Chap. 7 that for most of the nineteenth and early twentieth centuries, public policy was disposed towards "individualism and laissez-faire" (Keynes 1926, p. 272). That disposition was overturned when Keynes (1936) demonstrated that an economy will move to an equilibrium level of production that, under certain circumstances, can be influenced by the level of government spending. More than 80 years later, it is perhaps difficult to appreciate the radical shift represented by this insight. It implies a world of multiple equilibria, creating the possibility that the Nation State, acting as custodian of the market economy and welfare state, can aim to coordinate actions that will move the country towards an equilibrium that supports better wellbeing outcomes. ${ }^{2}$

This possibility can be illustrated by combining analyses in Chaps. 2 and 5 . Chap. 2 explained how personal skills are developed through a person discovering individual abilities, disciplining those abilities through education and displaying the disciplined abilities in contributions to wellbeing, including in employment (see Proposition 5). That model of personal skills is reproduced here in the upper diagram of Fig. 9.5.

In Chap. 5, Proposition 14 drew on the capability theory of the firm to state that firms combine different types of capital to maintain specialist capabilities for supplying goods and services valued by their customers. This was represented in Fig. 5.1, highlighting knowledge capital because of its centrality in the dynamic capabilities of an enterprise. That representation is reproduced in the lower diagram of Fig. 9.5. 

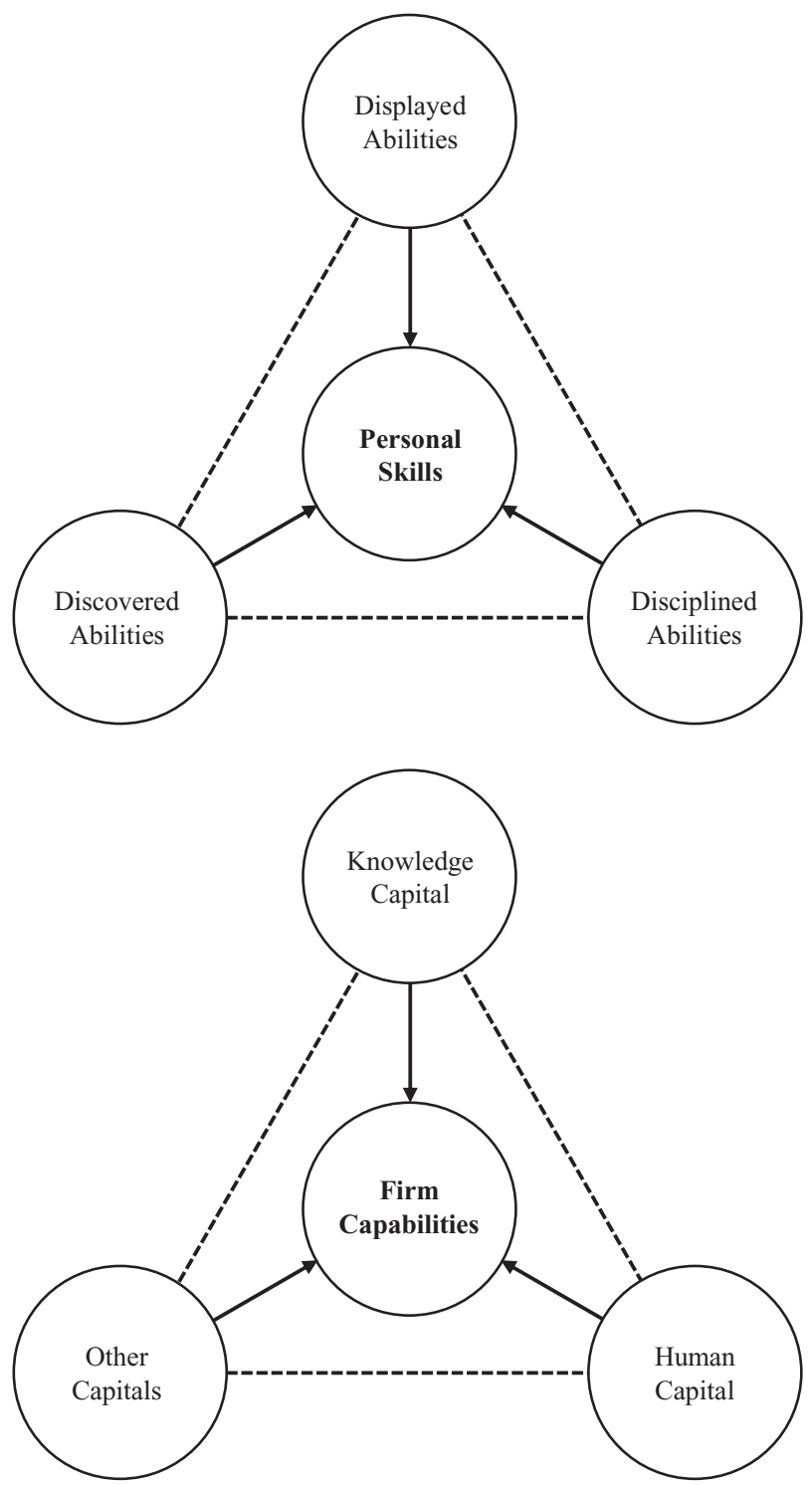

Fig. 9.5 Personal skills and firm capabilities. (Source: Figs. 2.2 and 5.1) 
Links between the upper and lower diagrams in Fig. 9.5 lead to two observations. First, the human capital drawn upon by a firm to contribute to its specialist capabilities (in the lower diagram) is the personal skills depicted at the centre of the upper diagram. Second, in this context of employment, the person's displayed abilities (in the upper diagram) contribute to the firm's capabilities at the centre of the lower diagram.

Figure 9.6 demonstrates these linkages, integrating the two parts of the previous figure into a single diagram. ${ }^{3}$ It shows pictorially that firms need skilled persons to sustain capabilities, and persons need to contribute to firm capabili-

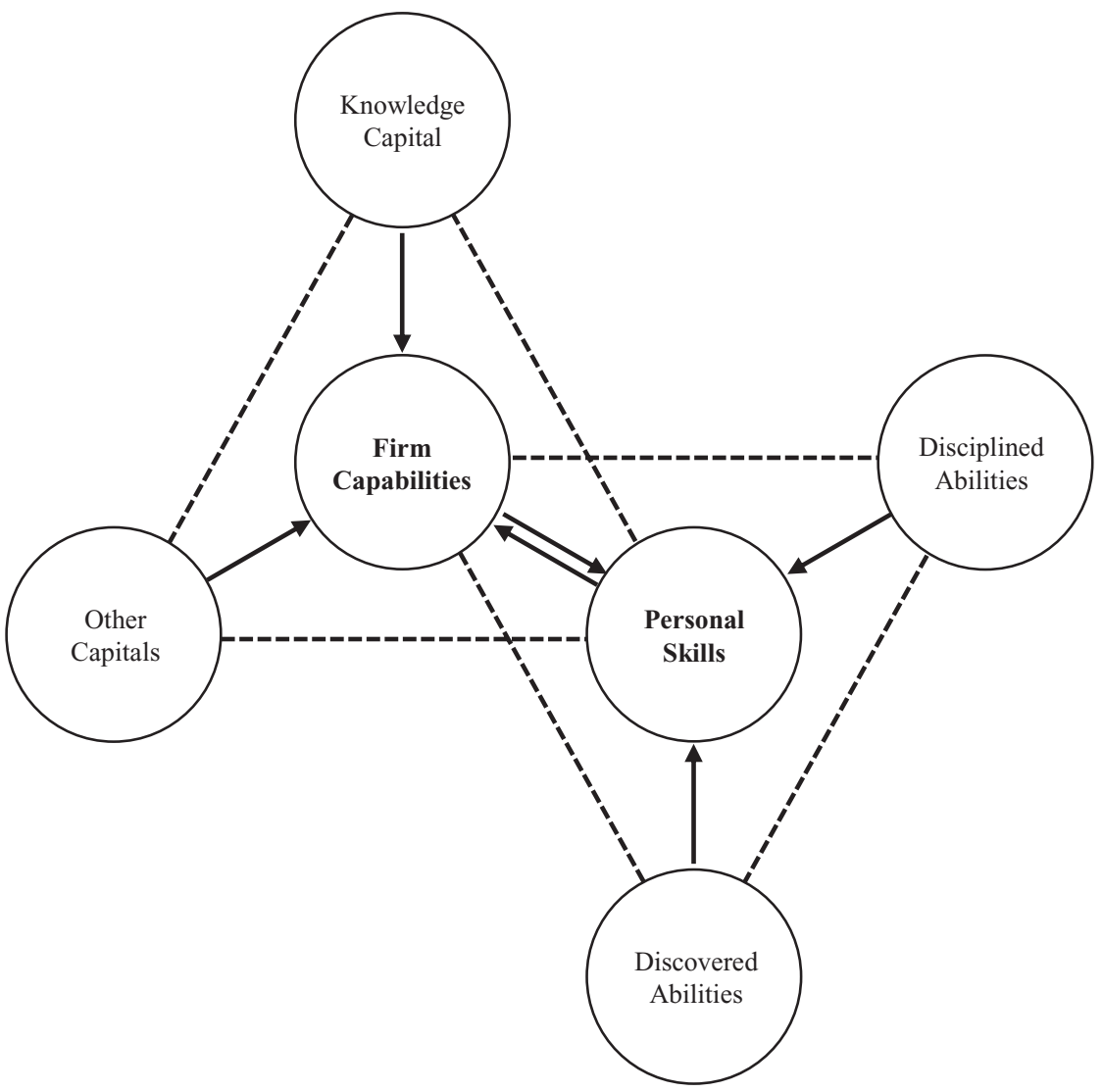

Fig. 9.6 Integration of personal skills and firm capabilities. (Source: Integration of the two diagrams in Fig. 9.5) 
ties to earn an economic reward for their investment in human capital. Personal skills and firm capabilities are reliant on each other. Thus, it is possible to imagine scenarios in which an industry settles on an equilibrium that involves low skills with weak capabilities, and other scenarios in which the equilibrium involves high skills and strong capabilities.

Public policy might therefore aim to move industry towards the high skill and strong capabilities equilibrium. The coordination problem revealed in Fig. 9.6 is that there is no direct link between the knowledge capital contributing to firm capabilities and the disciplined abilities contributing to personal skills. Consequently, to achieve an equilibrium characterised by firms with strong capabilities and employees with high skills, the state can construct a skill ecosystem that aims to match the evolving knowledge capital of firms with the evolving human capital developed in education institutions. ${ }^{4}$ As stated by UKCES (2009, p. 8): "There is little that is more important than equipping ourselves with the skills we need, for the jobs we need, for the successful businesses of tomorrow."

The above example considers just two types of capital (knowledge capital and human capital), but illustrates the difficulty of integrating policies to deliver better outcomes for wellbeing. The wellbeing fabric in Fig. 9.2 includes 7 types of capital and lists 11 outcomes for wellbeing. The task of integrating public policies to support investment in each type of capital, and ensuring that residents are able to access quality capital stocks to produce enhanced wellbeing outcomes, is very challenging. Nevertheless, if the primary purpose of economics is to contribute to enhanced wellbeing of persons (Proposition 1), then these challenges must be faced.

\section{Conclusion}

Chapter 1 began by citing Adam Smith's (1776) Wealth of Nations to argue that a focus on wellbeing has a long tradition in economics. This book is a contribution to that tradition. It has drawn on a wide literature to construct a wellbeing economics framework informed by the capabilities approach to prosperity.

The development of this framework has been motivated by the serious economic issues faced by the global community. These include achieving the United Nations' sustainable development goals, mitigating the urgent risks of climate change and addressing unequal access to economic resources within every country and between countries. It is no longer credible to presume that economic growth is the answer; indeed, current patterns of production growth have contributed to all of these problems. 
The wellbeing economics framework is a tool not only for decision-makers in local and national governments, but also for individuals, households and families, institutions of civil society and firms in the market economy. It provides an integrated approach for actions to expand the capabilities of persons to lead the kinds of lives they value, and have reason to value.

\section{Notes}

1. This term "wellbeing fabric" was first used in Dalziel et al. (2006, Table 2, p. 277) and Dalziel et al. (2009, Fig. 3, p. 15).

2. A recent discussion of the modelling difficulties created by multiple equilibria in a New Keynesian context is provided by Cochrane (2017).

3. Similar figures can be found in Dalziel $(2015,2017)$. The novel feature of this version is that it incorporates the capability theory of the firm.

4. See, for example, Crouch et al. (1999), Finegold (1999), Buchanan and Jakubauskas (2010), Buchanan et al. (2017) and Dalziel (2017).

\section{References}

Aizer, Anna. 2010. The Gender Wage Gap and Domestic Violence. American Economic Review 100 (4): 1847-1859.

Aldcroft, Derek H., and Michael J. Oliver. 2017. Trade Unions and the Economy: 1870-2000. London: Routledge.

Buchanan, John, and Michelle Jakubauskas. 2010. The Political Economy of Work and Skill in Australia: Insights from Recent Applied Research. In Beyond Skill, ed. Jane Bryson, 32-57. London: Palgrave Macmillan.

Buchanan, John, David Finegold, Ken Mayhew, and Chris Warhurst. 2017. Skills and Training: Multiple Targets, Shifting Terrain. In The Oxford Handbook of Skills and Training, ed. John Buchanan, David Finegold, Ken Mayhew, and Chris Warhurst, 1-14. Oxford: Oxford University Press.

Buunk, Abraham P., Justin H. Park, and Lesley A. Duncan. 2010. Cultural Variation in Parental Influence on Mate Choice. Cross-Cultural Research 44 (1): 23-40.

Cameron, Rt. Hon. David. 2010. PM Speech on Wellbeing. A Transcript of a Speech Given by the Prime Minister on 25 November 2010. https://www.gov.uk/ government/speeches/pm-speech-on-wellbeing.

Cochrane, John H. 2017. The New-Keynesian Liquidity Trap. Journal of Monetary Economics 92 (December): 47-63.

Crouch, Colin, David Finegold, and Mari Sako. 1999. Are Skills the Answer? Oxford: Oxford University Press. 
Dalziel, Paul. 2015. Regional Skill Ecosystems to Assist Young People Making Education Employment Linkages in Transition from School to Work. Local Economy 30 (1): 53-66.

. 2017. Education and Qualifications as Skills. In The Oxford Handbook of Skills and Training, ed. John Buchanan, David Finegold, Ken Mayhew, and Chris Warhurst, 143-160. Oxford: Oxford University Press.

Dalziel, Paul, Hirini Matunga, and Caroline Saunders. 2006. Cultural Well-Being and Local Government: Lessons from New Zealand. Australasian Journal of Regional Studies 12 (3): 267-280.

Dalziel, Paul and Caroline Saunders with Rosie Fyfe and Bronwyn Newton. 2009. Sustainable Development and Cultural Capital. Official Statistics Research Series 5. Available at http://hdl.handle.net/10182/2427.

Finegold, David. 1999. Creating Self-sustaining, Highskill Ecosystems. Oxford Review of Economic Policy 15 (1): 60-81.

IPCC. 2015. Climate Change 2014: Synthesis Report. Contribution of Working Groups I, II and III to the Fifth Assessment Report of the Intergovernmental Panel on Climate Change. Geneva: Intergovernmental Panel on Climate Change.

Jackson, Tim. 2017. Prosperity without Growth: Foundations for the Economy of Tomorrow. 2nd ed. Abingdon/New York: Routledge.

Keynes, John Maynard. 1926. The End of Laissez-Faire. Pamphlet Published by the Hogarth Press, Reprinted in and Cited from Donald Moggridge, Ed. The Collected Writings of John Maynard Keynes, Volume IX: Essays in Persuasion. London: Macmillan for the Royal Economic Society, 1972, pp. 272-294.

1936. The General Theory of Employment, Interest and Money, Reprinted in and Cited from Donald Moggridge, Ed. The Collected Writings of John Maynard Keynes, Volume VII: The General Theory. London: Macmillan for the Royal Economic Society, 1973.

Kraftl, Peter. 2012. Towards Geographies of 'Alternative' Education: A Case Study of UK Home Schooling Families. Transactions of the Institute of British Geographers 38 (3): 436-450.

Lyons, Sir Michael. 2007. Place-shaping: A Shared Ambition for the Future of Local Government. London: The Stationery Office.

Nussbaum, Martha C. 2000. Women and Human Development: The Capabilities Approach. Cambridge: Cambridge University Press.

- 2003. Capabilities as Fundamental Entitlements: Sen and Social Justice. Feminist Economics 9 (2-3): 33-59.

2011. Creating Capabilities: The Human Development Approach. Cambridge, MA: Belknap Press.

OECD. 2013. How's Life? 2013: Measuring Well-being. Paris: OECD Publishing https:// doi.org/10.1787/9789264201392-en.

2017. How's Life? 2017: Measuring Well-being. Paris: OECD Publishing https:// doi.org/10.1787/how_life-2017-en. 
Ostrom, Elinor. 2010. Beyond Markets and States: Polycentric Governance of Complex Economic Systems. American Economic Review 100 (3): 641-672.

Oswald, Andrew J. 1985. The Economic Theory of Trade Unions: An Introductory Survey. Scandinavian Journal of Economics 87 (2): 160-193.

Saunders, Caroline, and Paul Dalziel. 2004. Economic Well-being in Regional Economic Development. Australasian Journal of Regional Studies 10 (3): 355-366.

Sen, Amartya. 1983. Development: Which Way Now? Presidential Address of the Development Studies Association. Economic Journal 93 (December): 745-762.

-1999. Development as Freedom. Oxford: Oxford University Press.

- 2004. Capabilities, Lists, and Public Reason: Continuing the Conversation. Feminist Economics 10 (3): 77-80.

Shockley, Kristen M., Jill Douek, Christine R. Smith, P. Yu Peter, Soner Dumani, and Kimberly A. French. 2017. Cross-cultural Work and Family Research: A Review of the Literature. Journal of Vocational Behavior 101: 1-20.

Smith, Adam. 1776. An Enquiry into the Nature and Causes of the Wealth of Nations, 2 volumes, University Paperbacks edition, ed. Edwin Cannan. London: Methuen.

Solow, Robert M. 1956. A Contribution to the Theory of Economic Growth. Quarterly Journal of Economics 70 (1): 65-94.

Stiglitz, Joseph, Amartya Sen, and Jean-Paul Fitoussi. 2009. Report by the Commission on the Measurement of Economic Performance and Social Progress. https://www.insee.fr/ en/information/2662494. Accessed 16 July 2017.

Teece, David J. 2017a. Towards a Capability Theory of (Innovating) Firms: Implications for Management and Policy. Cambridge. Journal of Economics 41 (3): 693-720.

- 2017b. A Capability Theory of the Firm: An Economics and (Strategic) Management Perspective. New Zealand Economic Papers, forthcoming, https://doi. org/10.1080/00779954.2017.1371208.

Thompson, E.P. 1963. The Making of the English Working Class. London: Victor Gollancz. Tregenna, Fiona. 2009. Characterising Deindustrialisation: An Analysis of Changes in Manufacturing Employment and Output Internationally. Cambridge Journal of Economics 33 (3): 433-466.

UKCES. 2009. Towards Ambition 2020: Skills, Jobs, Growth. London: UK Commission for Employment and Skills.

van Neuss, Leif. 2018. Globalization and Deindustrialization in Advanced Countries. Structural Change and Economic Dynamics. Forthcoming, Available Online at https:// doi.org/10.1016/j.strueco.2018.02.002.

White, Sarah C. 2017. Relational Wellbeing: Re-centring the Politics of Happiness, Policy and the Self. Policy \& Politics 45 (2): 121-136. 
Open Access This chapter is licensed under the terms of the Creative Commons Attribution 4.0 International License (http://creativecommons.org/licenses/by/4.0/), which permits use, sharing, adaptation, distribution and reproduction in any medium or format, as long as you give appropriate credit to the original author(s) and the source, provide a link to the Creative Commons license and indicate if changes were made.

The images or other third party material in this chapter are included in the chapter's Creative Commons license, unless indicated otherwise in a credit line to the material. If material is not included in the chapter's Creative Commons license and your intended use is not permitted by statutory regulation or exceeds the permitted use, you will need to obtain permission directly from the copyright holder.

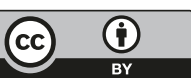

